\title{
Modeling of celiac disease immune response and the therapeutic effect of potential drugs
}

\author{
Oleg O Demin ${ }^{1 *}$, Sergey V Smirnov ${ }^{1}$, Victor V Sokolov ${ }^{1}$, Lourdes Cucurull-Sanchez ${ }^{2,3}$, Cesar Pichardo-Almarza ${ }^{2,4}$, \\ $M$ Victoria Flores ${ }^{2,5}$, Neil Benson ${ }^{2,6}$ and Oleg $\vee$ Demin $^{1}$
}

\begin{abstract}
Background: Celiac disease (CD) is an autoimmune disorder that occurs in genetically predisposed people and is caused by a reaction to the gluten protein found in wheat, which leads to intestinal villous atrophy. Currently there is no drug for treatment of CD. The only known treatment is lifelong gluten-free diet. The main aim of this work is to develop a mathematical model of the immune response in CD patients and to predict the efficacy of a transglutaminase-2 (TG-2) inhibitor as a potential drug for treatment of CD.
\end{abstract}

Results: A thorough analysis of the developed model provided the following results:

1. TG-2 inhibitor treatment leads to insignificant decrease in antibody levels, and hence remains higher than in healthy individuals.

2. TG-2 inhibitor treatment does not lead to any significant increase in villous area.

3. The model predicts that the most effective treatment of CD would be the use of gluten peptide analogs that antagonize the binding of immunogenic gluten peptides to APC. The model predicts that the treatment of CD by such gluten peptide analogs can lead to a decrease in antibody levels to those of normal healthy people, and to a significant increase in villous area.

Conclusions: The developed mathematical model of immune response in CD allows prediction of the efficacy of TG-2 inhibitors and other possible drugs for the treatment of CD: their influence on the intestinal villous area and on the antibody levels. The model also allows to understand what processes in the immune response have the strongest influence on the efficacy of different drugs. This model could be applied in the pharmaceutical R\&D arena for the design of drugs against autoimmune small intestine disorders and on the design of their corresponding clinical trials.

Keywords: Celiac disease, Mathematical modeling, Gluten, Drug development, Immune response

\section{Background}

Celiac disease $(\mathrm{CD})$ is an autoimmune disorder caused by the gluten protein contained in many grains. Upon entry of gluten into the small intestine, a patient develops painful digestion disorders due to villi impairment and loss of absorption. CD is partially a heritable disease [1]. The gene implicated in predisposition to CD (HLA DQ2 and DQ8) has a worldwide prevalence of around $1 \%$. At present there is no therapeutic agent to treat this disorder. The only approach able to minimize the CD

\footnotetext{
* Correspondence: demin_jr@insysbio.ru

${ }^{1}$ Institute for System Biology SPb, Moscow, Russia

Full list of author information is available at the end of the article
}

symptoms and currently used as prophylaxis is the strict compliance to a gluten-free diet (GFD), which consists on the removal of all gluten containing products, such as starchy and pasta from the diet, or the exchange of these products for products with a reduced gluten content [2]. Similar to many other autoimmune diseases, $\mathrm{CD}$ involves innate and adaptive immune responses $[3,4]$. The innate response causes a primary impairment of villi in the small intestine, increasing epithelial permeability allowing the entry of proteins from the lumen to the lamina propria [1]. The adaptive immune response

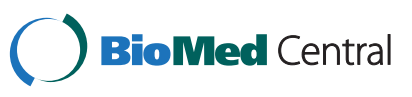

(c) 2013 Demin et al.; licensee BioMed Central Ltd. This is an Open Access article distributed under the terms of the Creative Commons Attribution License (http://creativecommons.org/licenses/by/2.0), which permits unrestricted use, distribution, and reproduction in any medium, provided the original work is properly cited. 
involves the binding of peptides and/or proteins present in the intestinal lamina propia to antigen-presenting cells (APCs) which leads to antibody production [1]. These peptides can undergo deamidation by the enzyme tissue transglutaminase (TG-2) [1], which in genetically predisposed individuals can boost the peptide immunogenicity [5,6]. This deamidation process enables the APCs to take up not only immunogenic peptides but also TG-2-peptide complexes. As a consequence, antibodies are produced not only against gluten peptides but also against TG-2 [7-10]. The two markers of CD are a decline in the villous area of the small intestine (i.e. villous breakdown), and the appearance of anti TG-2 antibody in plasma. This suggests that TG-2 is a key component of the disease and therefore a potential target candidate for $\mathrm{CD}$ therapy. Nevertheless, there are many unexplored aspects in $C D$ pathogenesis such as breakdown of oral tolerance and non DQ2/DQ8 ways of adaptive immune response stimulation.

To describe all intra- and extracellular processes associated with a disease and integrate heterogeneous sets of experimental data, a Quantitative Systems Pharmacology (QSP) modeling approach can be employed. This approach enables the description of a general mechanism of the immune response and its integration into the regulatory mechanisms characteristic of a disease of interest, in the current case CD. In addition, the QSP modeling approach provides a way for integrating the experimental data into a model to appropriately describe the disease of interest; with the aim of evaluating the most important processes and predicting potential targets for therapy.

A mathematical model of $\mathrm{CD}$ or its immune response has not yet been described in the literature. However, the mathematical modeling of a general immune response has been extensively performed and described, in particular the adaptive immune response, i.e. antigen presentation, synthesis, and activity of antibodies. The majority of the examples in the literature only describe general trends of the adaptive immune response to an antigen, without taking into account the complex regulatory mechanisms associated to the specific disease [11-14]. Just a limited number of publications focus on the adaptive immune response in the context of a disease mechanism in particular those induced by bacterial agents $[15,16]$. The work presented here intends to fill in these gaps by constructing a model of the innate and adaptive immune responses in CD. This model integrates all the human in vitro, ex vivo and in vivo data available, enabling the prediction of the efficacy of a TG-2 inhibitor, as well as the effect of other possible therapeutic agents on the levels of anti-TG-2 antibodies in plasma, and on the villous area in the small intestine.

\section{Methods}

Available experimental data, facts and assumptions used for model development

The model was constructed on the basis of the following experimental and literature information:

1) Healthy subjects do not have DQ2/DQ8 APCs [1].

2) Gluten peptides bind to receptors of intestinal epithelial cells (IEC), thus inducing zonulin synthesis that breaks down tight cell junctions $[17,18]$.

3) CD patients have a high level of intraepithelial lymphocytes (IEL), including activated IELs $[19,20]$.

4) Natural killers induce IEC apoptosis [21-23].

5) $\mathrm{CD}$ patients have an elevated level of interleukin-15 (IL-15) [24].

6) IL-15 promotes differentiation of APCs from monocytes, stimulates activation of IELs and arrests their apoptosis [24-26].

7) $T$ helpers of type 1 and type 17 are the main types of T-cells in adaptive immune response [1,27-29].

8) CD patients have an elevated level of interferon $\gamma$ (IFN- $\gamma$ ) in comparison to healthy individuals [30].

9) CD patients have an increased level of interleukin-21 (IL-21) relative to healthy individuals $[31,32]$.

10) IFN- $\gamma$ triggers IEC apoptosis [33].

11) IL-21 triggers IEC apoptosis [33].

12) IFN- $\gamma$ and IL-21 are synthesized by activated Tcells and activated IELs, i.e. natural killers [33-35].

13) CD patients test is positive for antibodies to gluten peptides and to TG-2 [10].

14) Antibodies to gluten peptides and TG-2 induce IEC apoptosis and inhibit their maturation [36].

15) $C D$ patients have higher constitutive expression of IL15 receptor alpha in comparison with healthy subjects [37]. Binding of IL-15 to these receptors leads to IEL activation

16) The threshold of IEL activation by IL-15 is lower in CD patients than that in healthy subjects [37-39].

17) $C D$ patients have higher zonulin level in comparison with healthy subjects $[40,41]$. In the development of this model the following assumptions were made:

a) T-helpers of types 1 and 17 are combined in one variable which is designated as T-cells.

b) Since the synthesis and degradation rates of IFN$\gamma$ and IL-21, as well as their action on IEC death are similar, IFN- $\gamma$ and IL-21 were merged into a single variable named as IF-21. The IF-21 synthesis rate was defined as combination of IFN$\gamma$ and IL-21 synthesis velocities, and the IF-21 degradation rate was set to the average between IFN- $\gamma$ and IL-21 degradation rates (see the section "Identification of model parameters" below). 
c) There are no both innate (based on clauses (3), (5), (15)-(17)) and adaptive (based on clause (1)) immune responses in healthy subjects. In the model describing healthy subjects IEC activation, IEL activation velocities are equal to zero and there are no differential equations for APC with DQ2/DQ8 histocompatibility complex. As a result, level of all activated cells, cytokines, zonulin and antibodies are equal to zero for healthy subjects.

d) The permeability of intestinal wall depends on zonulin level and number of IEC. Velocity of gluten peptides transport through intestine wall is equal to zero when there is no zonulin and level of IEC corresponds to healthy subject level. The influence of zonulin and IEC is described in additive manner (for more details see Additional file 1).

e) To take into account a delay in antibody production caused by $\mathrm{T}$ cells activation [42] and affinity maturation of B cells [43], a transient step in T-cell activation was introduced.

f) The arrival of gluten peptides into the lumen of healthy subjects and celiac disease patients on gluten-containing diet was considered constant rather than discrete and at a rate of 3 times per day, which would correspond to a normal daily food intake. It was set to the average inflow in a patient following a GFD diet, which according to the Codex Draft Revise Standard (2000) should contain less that $20 \mathrm{ppm}$ of gluten for foodstuffs naturally gluten-free (GF) and less than 200 ppm for foodstuffs rendered gluten-free (GF) [44].

\section{Scheme of the processes}

Based on the experimental data and assumptions stated above a network of processes was built, describing innate and adaptive immune responses in $C D$ patients (Figure 1). The innate immunity cascade begins with the binding of gluten peptides to IEC receptors (reaction \#5), thus activating them (see clause (2) in the previous section). These activated IECs produce zonulin and release it into the lumen (reaction \#31) and IL-15 into the lamina (reaction \#7) respectively. Zonulin promotes the disruption of tight junctions that control the permeability of macromolecules through the intestinal epithelial barrier (reaction \#13) (see clause (2)). IL-15 activates the IELs and inhibits their apoptosis (reaction \#10 and \#11) (see clause (6)). In accordance with clause (4) of the previous section, the activated IELs (natural killers) induce IEC apoptosis (reactions \#4 and \#6) and release various toxic proteins (granzymes, perforins, etc.). In addition, activated IELs produce IFN- $\gamma$ and IL-21 (reaction \#23) that also trigger IEC apoptosis (reactions \#4 and \#6) (see clauses (10)(12)). The disruption of the tight junctions and IEC death lead to the impairment of the epithelial barrier and an increase of its permeability, which allows the gluten peptides in the lumen to enter the lamina (reaction \#13).

When the peptides reach the lamina propria they can undergo deamidation by TG-2 [1] (reaction \#33).

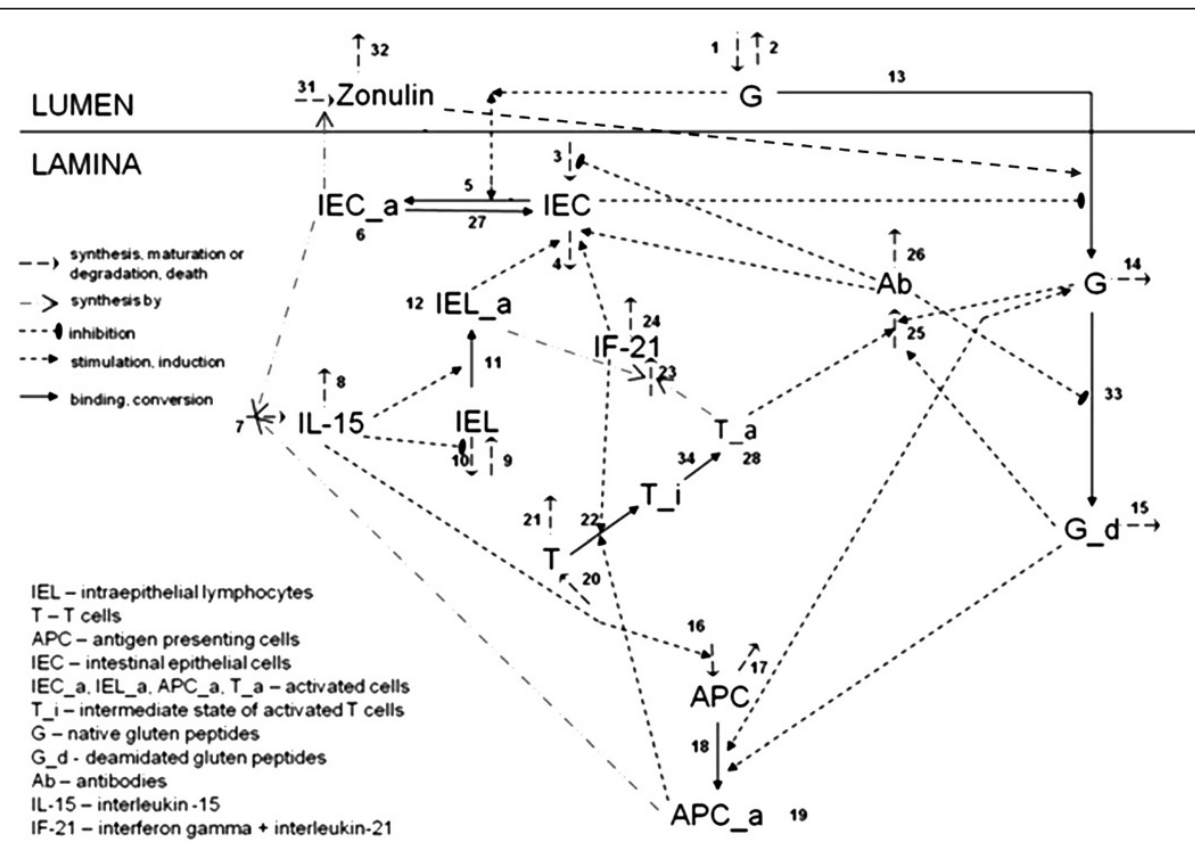

Figure 1 Network of processes of innate and adaptive immune responses described in the model. IEC activation (reaction \#5), IEL activation (reaction \#11) velocities are equal to zero and there are no differential equations for DQ2/DQ8 APC in the model for healthy subjects. 
Deamidated peptides are more immunogenic than native peptides $[5,6,45,46]$. IL-15, synthesized by activated IECs, stimulates the conversion of dendritic cells and monocytes into APCs with the definite histocompatibility complex DQ2/DQ8 (reaction \#16) (see clause (6)). These APCs bind both native and deamidated gluten peptides as well as deamidated gluten peptides complexed to TG-2 [1] (reaction \#18). As a result, TG-2 also becomes an antigen. Deamidated gluten peptides are more potent in APC activation than native peptides [5,46]. Those APCs that have taken up the antigen become activated, starting the production of IL-15 (reaction \#7) and stimulating T-cell activation (reaction \#22 and \#34) [33]. The activated T-cells synthesize IFN- $\gamma$ and IL-21 (reaction \#23) that in turn activate more T-cells (reaction \#22), forming a positive feedback loop. In addition, those activated T-cells (T-helpers types 1 and 17) considerably stimulate the production of antibodies specific to TG-2 and gluten peptides (reaction \#25), which in turn trigger the apoptosis of IECs and inhibit their maturation (reaction \#3, \#4 and \#6) [1,35,36].

\section{Model description}

All processes of immune response are described as system of ordinary differential equations:

$$
\frac{d \mathbf{x}}{d t}=\mathbf{N} \cdot \mathbf{v}, \quad \mathbf{x}(\mathbf{0})=\mathbf{x}_{\mathbf{0}}
$$

Here, $\mathbf{x}=\left[\mathrm{x}_{1}, \ldots, \mathrm{x}_{\mathrm{m}}\right]^{\mathrm{T}}$ is vector of model variables concentrations, $\mathbf{x}_{\mathbf{0}}=\left[\mathrm{x}_{10}, \ldots, \mathrm{x}_{\mathrm{mo}}\right]^{\mathrm{T}}$ is vector of initial concentrations of model variables, $\mathbf{v}=\left[\mathrm{v}_{1}, \ldots, \mathrm{v}_{\mathrm{n}}\right]^{\mathrm{T}}$ is vector of reaction rates, $\mathbf{N}$ is stoichiometric matrix which has $n$ columns and $m$ rows. Detailed description of system of differential equations and reaction velocities are presented in Additional file 1.

Overall, the model has a total of 16 variables and 54 parameters. Variables are listed in Additional file 1: Table S1. Parameters, their values, and a description of the source from which the values were obtained are presented in section "Identification of model parameters" and listed in Additional file 1: Table S2.

\section{Identification of model parameters}

As stated in the section "Scheme of the processes" the reaction rate expressions contain 54 parameters. A portion of these parameters was either taken directly from literature sources or estimated from literature data. Seventeen parameters were determined via the latter approach, amongst them the death constant of APCs, the degradation constant of gluten peptides, the dissociation constant of gliadin from IEC receptors, and the portion of receptors to be occupied by gluten peptides to activate IECs. Values of 2 parameters were assumed and 4 parameters were calculated using experimental data. These parameters and their corresponding values are given in Additional file 1: Table S2. The other 31 parameters were evaluated based on the best fitting to the appropriate experimental data, using the Hook-Jeeves method as implemented in the DBSolve Optimum package $[47,48]$. As a criterion of goodness of fit, the sum of squares error function was used: $f\left(k_{j}, K_{j}\right)=\sum_{i}^{n}\left(v_{i}-\bar{v}_{i}\right)^{2}$

Where $n$ is the total number of experimental points, $\bar{v}_{i}$ is the experimentally measured value of the variable or reaction rate, $v_{i}$ is the corresponding value estimated from the model, $k_{j}, K_{j}$ are unknown parameters. To estimate the values of the unknown parameters, the error function $(f)$ was minimized.

Given the large number of unknown parameters contained in the model, it was necessary to fit them against the maximum possible experimental data points and calculate the range of possible parameter values. Therefore data was extracted from in vitro and ex vivo studies, as well as clinical studies in patients at various stages of $\mathrm{CD}$, and $95 \%$ confidential intervals were calculated for fitted parameters using method described in [49] (see Additional file 1: Table S2).

\section{Results}

\section{Model validation}

The appropriate choice of model parameters was verified against independent data that had not been used in the identification of the model parameters. In fact, it is known that after changing over from a gluten-containing diet to a gluten-free diet the antibody level drops to the background level (in the model to zero level) within 2 to 4 months [50]. After changing over from a GFD to a gluten-containing diet, antibodies appear within 2 to 4 weeks [51]. Simulations of these two scenarios led to the following predictions: (i) after changing over from a gluten-containing diet to a GFD the antibody level drops nearly to zero within 2 to 3 months (Figure 2), (ii) after changing over from a GFD to a gluten-containing diet antibodies appear within 2 weeks (Figure 3). These temporal characteristics of transient processes, based on model calculations, are consistent with clinical data.

\section{Prediction of efficacy of various potential drugs to treat celiac disease}

The model developed herein was used to predict the TG-2 inhibitor activity and other potential therapeutic agents for $\mathrm{CD}$ such as antibodies against IFN- $\gamma$ and IL-15, gluten peptide-related agents that arrest activation of APCs (DQ2 blocking peptide analogues) [52-55], and gluten peptide-related agents that repress IEC activation (permeability inhibitors) [56]. The efficacy of each therapy was 


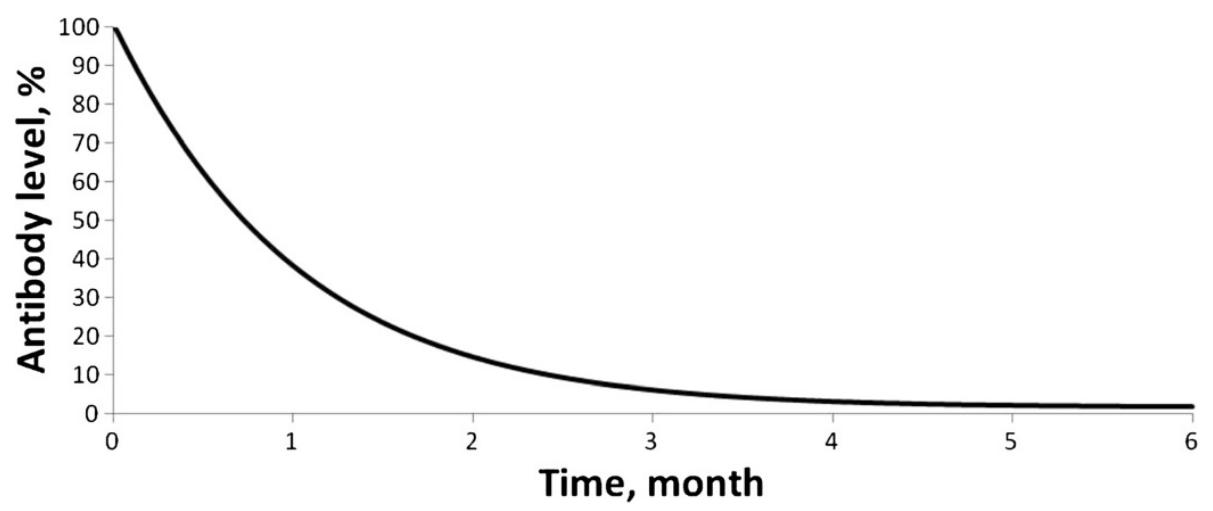

Figure 2 Decreasing of antibodies level after changing diet from gluten-containing to gluten-free.

measured in terms of antibody levels and villous area levels. The antibody level was measured as a percentage, whereby $100 \%$ corresponds to the steady-state level of a patient on a gluten-containing diet. For a patient on a GFD and for a healthy patient the antibody levels are close to and equal to zero, respectively.

\section{TG-2 inhibitor}

To model the activity of a TG-2 inhibitor, the TG-2 level in the lamina propria was decreased. It was found that when the TG-2 level reaches zero, i.e. upon complete inhibition, the antibody levels only decrease to $70-75 \%$ (Figure 4a). Likewise, the complete inhibition of TG-2 does not cause a significant increase in the villous area: from 10 to $14 \%$ (Figure 4b).

Next, an analysis was performed to determine what processes most significantly influence the efficacy of TG-2 inhibitors. It turned out that the most important process was the activation of APCs and B-cells by peptides binding to it. It is known from the literature that the EC50 of APC activation by deamidated peptides is 5 -fold lower than by native peptides, i.e. deamidated proteins are more immunogenic [5,6]. However, these data cannot be considered unambiguous since the ratio of EC50 between deamidated and native forms varies with different gluten peptides [6]. So a series of simulations was run where the EC50 of the deamidated peptides was fixed and the EC50 of the native peptides was expressed as an increasing $n$-fold value of it. Every time the native to deamidated EC50 ratio was increased, the model was re-validated ( $k_{s}^{a b}$ was increased) since the antibody level declined due to a reduction in the immunogenicity of the native peptides. Overall, by increasing the native to deamidated EC50 ratio, the role of TG-2 in the immunogenicity of peptides becomes more important. The results shown that the antibody levels drop to or near zero at ratio values of 80 -fold or greater (Figure 5), and no significant expansion of the villous area was observed.

\section{IFN- $\gamma$ antibodies}

To model the activity of IFN- $\gamma$ antibodies, the degradation rate constant of IF-21 (IFN- $\gamma+$ IL-21) was increased. As a result, considering the maximum possible breakdown rate (i.e. when the IF-21 concentration decreased to zero) the antibody levels dropped to $83 \%$

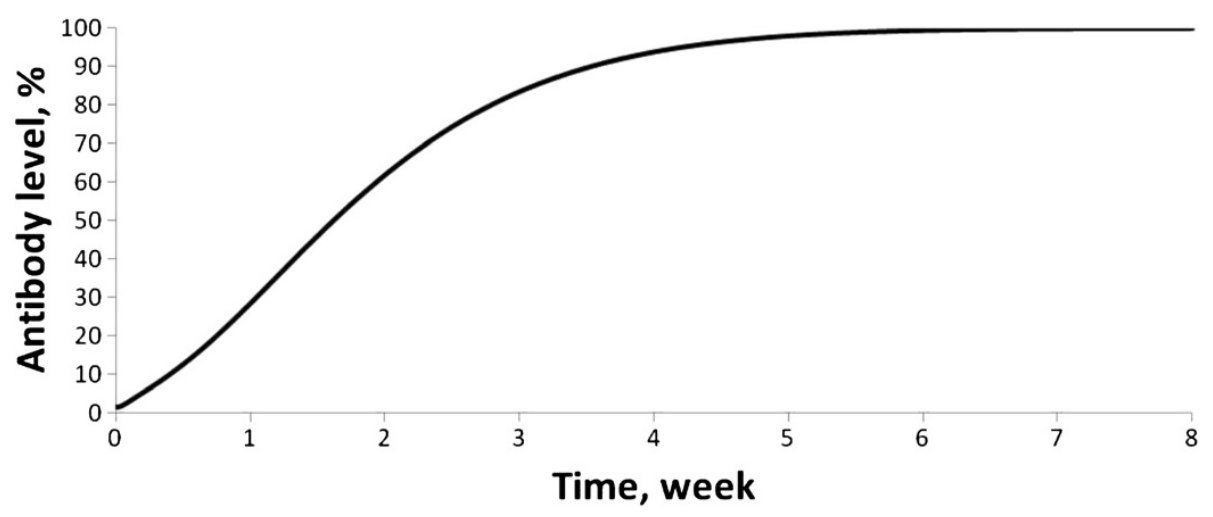

Figure 3 Appearance of antibodies after changing diet from gluten-free to gluten-containing. 

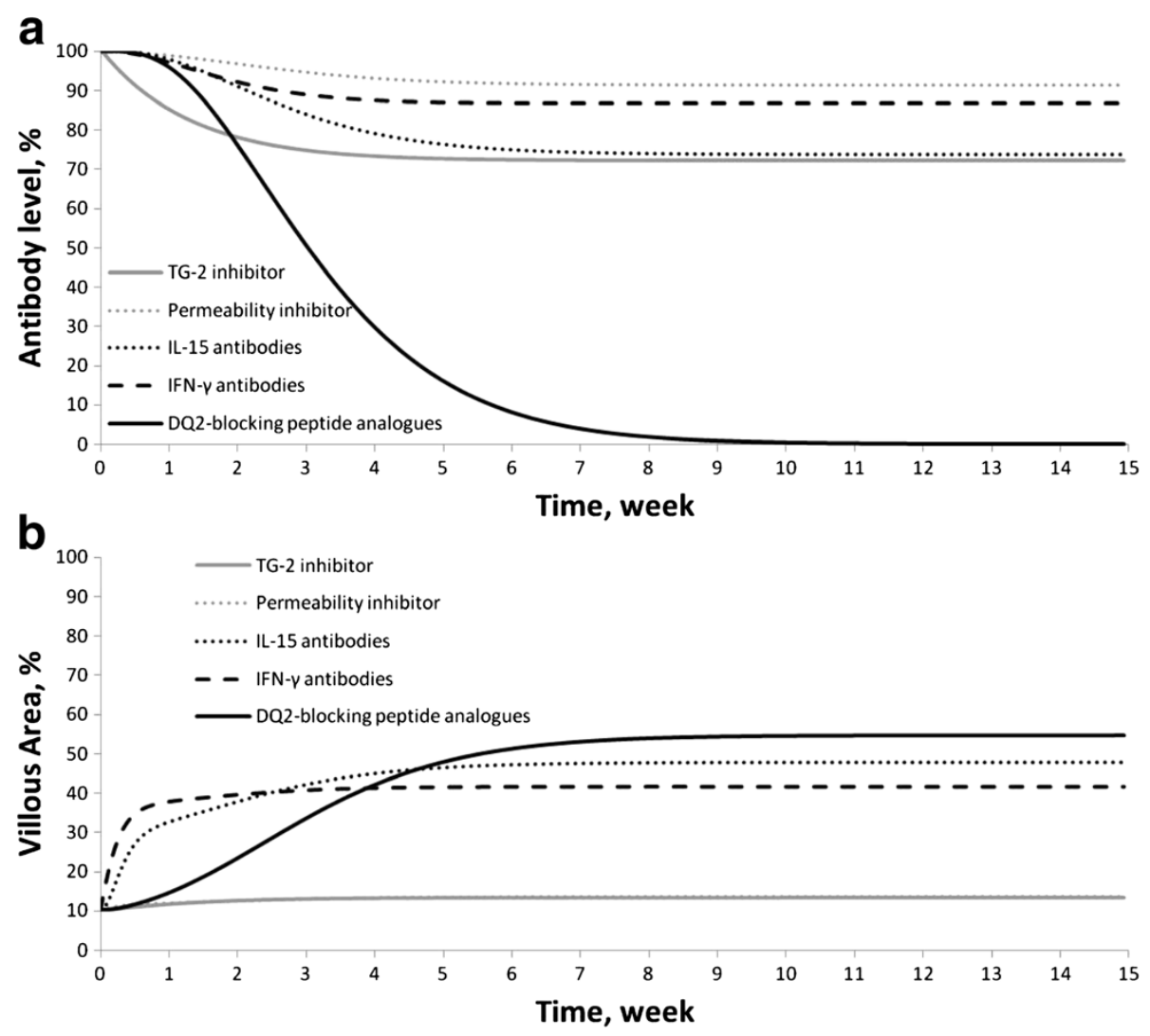

Figure 4 (a) Decreasing of antibodies level during treatment by different potential therapeutic agents; (b) Increasing of VA during treatment by different potential therapeutic agents (Curve for Permeability inhibitor coincides with curve for TG2 inhibitor).

(Figure 4a) and the villous area increased up to $40 \%$ (Figure 4b).

\section{IL-15 antibodies}

To model the activity of IL- 15 antibodies the degradation rate constant of IL-15 was increased. At the maximum possible degradation rate (i.e. when IL-15 concentration decreased to zero) the antibody levels dropped to $69 \%$
(Figure 4a) and the villous area increased up to $46 \%$ (Figure 4b).

\section{Gluten peptide-related agents that repress IEC activation (permeability inhibitors)}

To model the activity of gluten peptides analogues the activation rate constant of IECs was set to zero. Consequently the antibody levels dropped to 92\% (Figure 4a) and the villous area increased up to $14 \%$ (Figure $4 \mathrm{~b}$ ).

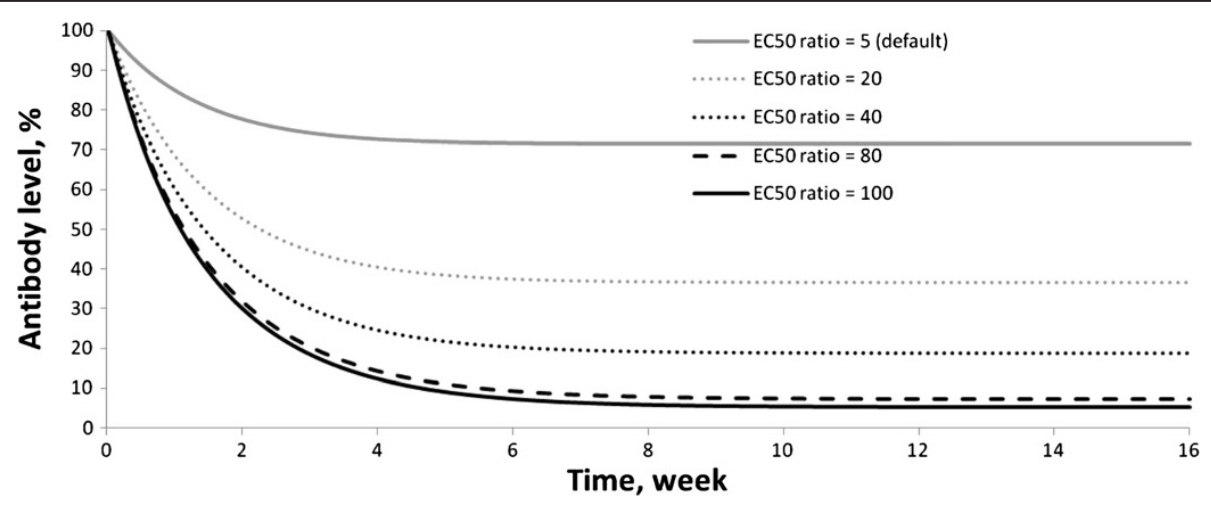

Figure 5 Decreasing of antibodies level during TG-2 inhibitor treatment at different EC50 ratio. 


\section{Gluten peptide-related agents that arrest activation of APCs (DQ2-blocking peptide analogues)}

To model the activity of these analogues of gluten peptides the activation rate constant of APCs was set to zero. Consequently, the antibody levels dropped to zero (Figure 4a) and the villous area increased up to $51 \%$ (Figure 4b).

\section{Discussion}

$\mathrm{CD}$ is a complex autoimmune disorder with many unexplored aspects. Role and contribution of various possible mechanisms (disruption of "central", "peripheral" tolerances, $\mathrm{T}$ cell anergy, etc.) to oral tolerance breakdown, $\mathrm{CD}$ pathogenesis and severity is not established yet. There are different possible ways of gluten peptides transfer into the lamina propria [57]. They could cross the intestinal epithelium either via the paracellular route or via the transcellular route. In the first case this occurs as a consequence of an increased permeability, in the second case it occurs by using enterocytic vesicles that are able to cross the basal membrane allowing intact gluten peptides to have access to the lamina propria. It is known that one of the main cause of $\mathrm{CD}$ is the presence of HLA DQ2 and DQ8 molecules, but 1-2\% of CD patients do not have DQ2 and/or DQ8 [51]. So there could be non DQ2/DQ8 ways of immune response stimulation. In our model the mechanism of oral tolerance breakdown has not been considered. We take into account only DQ2/DQ8 route of immune response stimulation and paracellular way of gluten peptides transfer into lamina propria. To describe healthy patients we use the assumption that there are no innate and adaptive immune responses in healthy subject (see section "Methods"). This approach allows us to simplify the equations of our model and to decrease the number of model parameters. The detailed description of mechanisms of IEL activation, transport of gluten peptides through intestine wall, interaction of peptides with non DQ2/DQ8 APC in healthy subjects could help to study and understand more clear the processes underlying the absence of immune responses in healthy subjects. This could be the next step for modeling of immune response in human.

The model described in this manuscript was able to predict that a TG-2 inhibitor can reduce the antibody levels down to zero if the deamidated peptides are more immunogenic than the native peptides, i.e. if the EC50 of deamidated peptides binding to APCs and B-cells is 80 -fold lower or less than for native peptides. However, a TG-2 inhibitor would not significantly increase the villous area because the influence of antibodies on IEC death and inhibition of their maturation is insignificant. This is logical given that the villous area in a patient on a GFD was experimentally shown to be $50 \%$ of that in a healthy patient. It is known that in a patient following GFD the antibody levels are similar to the background antibody levels of a healthy patient (i.e. it equals to zero in the model). It follows from this that a 2 -fold reduction in the villous area (from $100 \%$ to $50 \%$ ) is due to IELs and IFN- $\gamma$, to a lesser extent, zonulin. After changing over from GFD to gluten-containing diet, the villous area decreases from $50 \%$ to $10 \%$. This can be attributed to an increase in the levels of IELs and IFN- $\gamma$ that trigger IEC apoptosis, as well as to the action of IL21 and the antibodies. Overall, even if one suggests that the reduction from $50 \%$ to $10 \%$ only occurs through antibodies, then upon the condition that deamidated peptides are significantly more immunogenic than native ones (the EC50 ratio is 1:80 or greater), the TG-2 inhibitor induces a state similar to that of a GFD (in terms of both the antibody level and the villous area).

An evaluation of the efficacy of various potential drugs to treat $C D$ suggests that the most efficient therapeutic agents would be analogues of immunogenic peptides that repress activation of APCs. This is logical as activated APCs play a key role in the adaptive immune response and maintenance of the activity of effectors of the innate immune response. Activated APCs release IL15 that in turn arrests IELs death and at the same time induce their activation, i.e. stimulates differentiation of natural killers from IELs triggering apoptosis. As a conclusion, by arresting APC activation it seems that the synthesis of antibodies can be completely shut down and the concentrations of activated IELs, IFN- $\gamma$, and IL-21 significantly decreased, resulting in an increase of the villous area up to $51 \%$.

One type of promising agents for $\mathrm{CD}$ therapy, the analogues of immunogenic peptides that repress IEC activation, appeared to be less efficient than GFD. These analogues arrest IEC activation, which represses the synthesis of zonulin and IL-15. However, this has no significant effect on effectors of the adaptive immune response. Activated APCs continue the synthesis of IL15, activating IELs and T-cells, both of which trigger the release of IFN- $\gamma$ and IL-21. The antibody level, which depend directly and exclusively on the number of activated T-cells and the amount of gluten peptides in the lamina propria, remain nearly the same as in the absence of peptide analogues. The villous area, increases only up to $14 \%$ due to the absence of zonulin, and a limited reduction in the concentration of activated IELs, IFN- $\gamma$ and IL-21.

Significant reduction in IFN- $\gamma$ and IL-15 level (resulted from administration of corresponding specific antibodies, for example) leads to the small decrease in antibody level. This can be explained in terms of auxiliary role of the cytokines in adaptive immune response. Indeed, IFN- $\gamma$ is involved in $\mathrm{T}$ cells activation and 
elevation of IFN- $\gamma$ results in increase in rate of $\mathrm{T}$ cells activation by some extent but even complete depletion of IFN- $\gamma$ does not lead to stop in T cell activation. IL-15 is involved in differentiation of APCs from monocytes. Elevation in IL-15 is able to increase the rate of differentiation of APCs from monocytes but there is other IL-15 independent ways of replenishment of APC population. At the same time, decrease in IFN- $\gamma$ and IL-15 levels results in significant increase of villous area (up to $40 \%$ and $46 \%$ respectively) because of the significant influence of IFN- $\gamma$ and IL-21 on IEC apoptosis and strong stimulation effect of IL-15 on IEL activation.

The robustness of model predictions was analyzed in the following manner. We simulated villous area and antibody level during different treatments taking the value of model parameters from the confidential intervals identified using method described in section "Simulations on the range of parameter's confidential intervals" (Additional file 1). Results are presented in Additional file 1: Figure S15-24. From the analysis we can conclude that model predictions of influence of TG-2 inhibitor, permeability inhibitor, DQ-2 blocking peptides on villous are and antibody level and IFN- $\gamma$, IL-15 antibodies on antibody level are quite robust to variation in model parameters. On the other hand, robustness of the model predictions for IFN- $\gamma$ (Additional file 1: Figure S22) and IL-15 (Additional file 1: Figure S23) antibodies influence on villous area is not satisfactory. This can be explained in terms of lack of sufficient amount of available experimental data required for reliable identification of parameter values responsible for the processes associated with contribution of IFN- $\gamma$ and IL-15 to immune response in CD. This pushes us to state that model of celiac disease developed in our manuscript can be applied to identify gaps in experimental and clinical data and to initiate more quantitative and rational exploration of the processes involved in CD pathogenesis. Taking these gaps in experimental/ clinical data in mind model can advise on optimal design of clinical study or experiment $[58,59]$.

\section{Conclusions}

Overall, the use of antibodies against IFN- $\gamma$, and IL-15, analogues of gluten peptides repressing IEC activation, and TG-2 inhibitor would not be efficient solutions to treat $C D$. The model indicates that the most efficient therapeutic agent is a product that acts on species involved in both the innate and the adaptive immune response, i.e. analogues of gluten peptides that arrest APC activation. This model could be applied in the pharmaceutical R\&D arena for the design of drugs against autoimmune small intestine disorders and on the design of their corresponding clinical trials.

\section{Additional file}

Additional file 1: Detailed description of the model system of differential equations, rate laws and model verification. List of model parameters and variables.

\section{Abbreviations}

CD: Celiac disease; TG-2: Transglutaminase-2; GFD: Gluten free diet; QSP: Quantitative systems pharmacology; IEC: Intestinal epithelial cells; IEL: Intraepithelial lymphocytes, aka. natural killers; IL-15: Interleukin-15; IL-21: Interleukin-21; IFN- $\gamma$ : Interferon $\gamma ;$ IF-21: Single variable that represents both IFN- $\gamma$ and IL-21; APC: Antigen-presenting cell.

\section{Competing interests}

The authors declare that they have no competing interests.

\section{Authors' contributions}

OOD developed celiac disease immune response model, verified it and ran model simulations; SVS participated in model development and verification; WS participated in model verification and ran model simulations; LC, CP, MVF, NB and OVD participated in study design and coordination and helped to draft the manuscript. All authors read and approved the final manuscript.

\section{Acknowledgements}

We would like to thank Nail Gizzatkulov and Evgeny Metelkin for help with calculations.

\section{Author details}

${ }^{1}$ Institute for System Biology SPb, Moscow, Russia. ${ }^{2}$ Pfizer Global R\&D, Sandwich, UK. ${ }^{3}$ Present affiliation: GlaxoSmithKline Medicines Research Centre, Stevenage, UK. ${ }^{4}$ Present affiliation: InScilico Ltd, London, UK. ${ }^{5}$ Present affiliation: eTherapeutics plc, Long Hanborough, UK. ${ }^{6}$ Present affiliation: Xenologiq Ltd, Canterbury, UK.

Received: 13 February 2013 Accepted: 27 June 2013

Published: 5 July 2013

\section{References}

1. Schuppan D: Current concepts of celiac disease pathogenesis. Gastroenterology 2000, 119:234-242.

2. Tennyson CA, Suzanne K, Green L, Green P: New and developing therapies for celiac disease. Ther Adv Gastroenterol 2009, 2:303-309.

3. Gianfrani C, Auricchio S, Troncone R: Adaptive and innate immune responses in celiac disease. Immunol Lett 2005, 99:141-145.

4. Stepniak D, Koning F: Celiac disease-sandwiched between innate and adaptive immunity. Hum Immunol 2006, 67:460-468.

5. Shan L, Molberg O, Parrot I, Hausch F, Filiz F, Gray GM, Sollid LM, Khosla C: Structural basis for gluten intolerance in celiac sprue. Science 2002, 297:2275-2279.

6. Tollefsen S, Arentz-Hansen H, Fleckenstein B, Molberg O, Ra'ki M, Kwok WW, Jung G, Lundin KE, Sollid LM: HLA-DQ2 and -DQ8 signatures of gluten T cell epitopes in celiac disease. J Clin Invest 2006, 116:2226-2236.

7. Bethune MT, Ribka E, Khosla C, Sestak K: Transepithelial transport and enzymatic detoxification of gluten in gluten-sensitive rhesus macaques. PLOS One 2008, 3:e1857.

8. Byrne G, Feighery C, Jackson J, Kelly J: Coeliac disease autoantibodies mediate significant inhibition of tissue transglutaminase. Clin Immunol 2010, 136:426-431.

9. Colombel JF, Mascart-Lemone F, Nemeth J, Vaerman JP, Dive C, Rambaud JC: Jejunal immunoglobulin and antigliadin antibody secretion in adult coeliac disease. Gut 1990, 31:1345-1349.

10. Ankelo M, Kleimola V, Simell S, Simell O, Knip M, Jokisalo E, Tarkia M, Westerlund A, He Q, Viander M, Ilonen J, Hinkkanen AE: Antibody responses to deamidated gliadin peptide show high specificity and parallel antibodies to tissue transglutaminase in developing coeliac disease. Clin Exp Immunol 2007, 150:285-293.

11. Gutnikov S, Melnikov $Y$ : A simple non-linear model of immune response. Chaos Solitons \& Fractals 2003, 16:125-132.

12. Dibrov BF, Livshits MA, Volkenstein MV: Mathematical model of immune processes. J Theor Biol 1977, 65:609-631. 
13. Stengel RF, Ghigliazza RM, Kulkarni NV: Optimal enhancement of immune response. Bioinformatics 2002, 18:1227-1235.

14. Bruni C, Giovenco MA, Koch G, Strom R: A dynamical model of humoral immune response. Math Biosci 1975, 27:191-211.

15. Marino S, Pawar S, Fuller CL, Reinhart TA, Flynn JL, Kirschner DE: Dendritic cell trafficking and antigen presentation in the human immune response to Mycobacterium tuberculosis. J Immunol 2004, 173:494-506.

16. Wilson DP, Timms P, McElwain DL: A mathematical model for the investigation of the Th1 immune response to Chlamydia trachomatis. Math Biosci 2003, 182:27-44.

17. Lammers KM, Lu R, Brownley J, Lu B, Gerard C, Thomas K, Rallabhandi P, Shea-Donohue T, Tamiz A, Alkan S, Netzel-Arnett S, Antalis T, Vogel SN, Fasano A: Gliadin induces an increase in intestinal permeability and zonulin release by binding to the chemokine receptor CXCR3. Gastroenterology 2008, 135:194-204.

18. Drago S, El Asmar R, Di Pierro M, Grazia Clemente M, Tripathi A, Sapone A, Thakar M, lacono G, Carroccio A, D'Agate C, Not T, Zampini L, Catassi C, Fasano A: Gliadin, zonulin and gut permeability: Effects on celiac and non-celiac intestinal mucosa and intestinal cell lines. Scand J Gastroenterol 2006, 41:408-419.

19. Ferguson A, Murray D: Quantitation of intraepithelial lymphocytes in human jejunum. Gut 1971, 12:988-994.

20. Mazzarella G, Maglio M, Paparo F, Nardone G, Stefanile R, Greco L, van de Wal Y, Kooy Y, Koning F, Auricchio S, Troncone R: An immunodominant DQ8 restricted gliadin peptide activates small intestinal immune response in in vitro cultured mucosa from HLA-DQ8 positive but not HLA-DQ8 negative coeliac patients. Gut 2003, 52:57-62.

21. Meresse B, Chen Z, Ciszewski C, Tretiakova M, Bhagat G, Krausz TN, Raulet DH, Lanier LL, Groh V, Spies T, Ebert EC, Green PH, Jabri B: Coordinated induction by IL15 of a TCR-independent NKG2D signaling pathway converts CTL into lymphokine-activated killer cells in celiac disease. Immunity 2004, 21:357-366.

22. Hue S, Mention JJ, Monteiro RC, Zhang S, Cellier C, Schmitz J, Verkarre V, Fodil N, Bahram S, Cerf-Bensussan N, Caillat-Zucman S: A direct role for NKG2D/MICA interaction in villous atrophy during celiac disease. Immunity 2004, 21:367-377.

23. Ebert EC: IL-15 converts human intestinal intraepithelial lymphocytes to CD94 producers of IFN-gamma and IL-10, the latter promoting Fas ligand-mediated cytotoxicity. Immunology 2005, 115:118-126.

24. Di Sabatino A, Ciccocioppo R, Cupelli F, Cinque B, Millimaggi D, Clarkson MM, Paulli M, Cifone MG, Corazza GR: Epithelium derived interleukin 15 regulates intraepithelial lymphocyte Th1 cytokine production, cytotoxicity, and survival in coeliac disease. Gut 2006, 55:469-477.

25. Harris KM, Fasano A, Mann DL: Monocytes differentiated with IL-15 support Th17 and Th1 responses to wheat gliadin: implications for celiac disease. Clin Immunol 2010, 135:430-439.

26. Regamey N, Obregon C, Ferrari-Lacraz S, van Leer C, Chanson M, Nicod LP, Geiser T: Airway epithelial IL-15 transforms monocytes into dendritic cells. Am J Respir Cell Mol Biol 2007, 37:75-84.

27. Castellanos-Rubio A, Santin I, Irastorza I, Castano L, Carlos Vitoria J, Ramon Bilbao J: TH17 (and TH1) signatures of intestinal biopsies of CD patients in response to gliadin. Autoimmunity 2009, 42:69-73.

28. Kamada N, Hisamatsu T, Honda H, Kobayashi T, Chinen H, Kitazume MT, Takayama T, Okamoto S, Koganei K, Sugita A, Kanai T, Hibi T: Human CD14 + macrophages in intestinal lamina propria exhibit potent antigenpresenting ability. J Immunol 2009, 183:1724-1731.

29. Kleinschek MA, Boniface K, Sadekova S, Grein J, Murphy EE, Turner SP, Raskin L, Desai B, Faubion WA, de Waal Malefyt R, Pierce RH, McClanahan T, Kastelein RA: Circulating and gut-resident human Th17 cells express CD161 and promote intestinal inflammation. J Exp Med 2009. 206:525-534.

30. Manavalan JS, Hernandez L, Shah JG, Konikkara J, Naiyer AJ, Lee AR, Ciaccio E, Minaya MT, Green PH, Bhagat G: Serum cytokine elevations in celiac disease: association with disease presentation. Hum Immunol 2010, 71:50-57.

31. Meresse B, Verdier J, Cerf-Bensussan N: The cytokine interleukin 21: a new player in coeliac disease? Gut 2008, 57:879-881.

32. Schmitt N, Morita R, Bourdery L, Bentebibel SE, Zurawski SM, Banchereau J, Ueno H: Human dendritic cells induce the differentiation of interleukin21-producing $T$ follicular helper-like cells through interleukin-12. Immunity 2009, 31:158-169.
33. De Nitto D, Monteleone I, Franze E, Pallone F, Monteleone G: Involvement of interleukin-15 and interleukin-21, two gamma-chain-related cytokines, in celiac disease. World J Gastroenterol 2009, 15:4609-4614.

34. Coquet JM, Kyparissoudis K, Pellicci DG, Besra G, Berzins SP, Smyth MJ, Godfrey DI: IL-21 is produced by NKT cells and modulates NKT cell activation and cytokine production. J Immunol 2007, 178:2827-2834.

35. Wei L, Laurence A, Elias KM, O'Shea JJ: IL-21 is produced by Th17 cells and drives IL-17 production in a STAT3-dependent manner. J Biol Chem 2007, 282:34605-34610.

36. Caputo I, Barone MV, Martucciello S, Lepretti M, Esposito C: Tissue transglutaminase in celiac disease: role of autoantibodies. Amino Acids 2009, 36:693-699.

37. Bernardo D, Garrote JA, Allegretti Y, Leon A, Gomez E, Bermejo-Martin JF, Calvo C, Riestra S, Fernandez-Salazar L, Blanco-Quiros A, Chirdo F, Arranz E: Higher constitutive IL15R alpha expression and lower IL-15 response threshold in coeliac disease patients. Clin Exp Immunol 2008, 154:64-73.

38. Liu Z, Geboes K, Colpaert S, D'Haens GR, Rutgeerts P, Ceuppens JL: IL-15 is highly expressed in inflammatory bowel disease and regulates local T cell-dependent cytokine production. J Immunol 2000, 164:3608-3615.

39. Mention JJ, Ben Ahmed M, Begue B, Barbe U, Verkarre V, Asnafi V, Colombel JF, Cugnenc PH, Ruemmele FM, McIntyre E, Brousse N, Cellier C, CerfBensussan N: Interleukin 15: a key to disrupted intraepithelial lymphocyte homeostasis and lymphomagenesis in celiac disease. Gastroenterology 2003, 125:730-745

40. Sapone A, de Magistris L, Pietzak M, Clemente MG, Tripathi A, Cucca F, Lampis R, Kryszak D, Carteni M, Generoso M, lafusco D, Prisco F, Laghi F, Riegler G, Carratu R, Counts D, Fasano A: Zonulin upregulation is associated with increased gut permeability in subjects with type 1 diabetes and their relatives. Diabetes 2006, 55:1443-1449.

41. Smecuol E, Sugai E, Niveloni S, Vazquez H, Pedreira S, Mazure R, Moreno ML, Label M, Maurico E, Fasano A, Meddings J, Bai JC: Permeability, zonulin production, and enteropathy in dermatitis herpetiformis. Clin Gastroenterol Hepatol 2005, 3:335-341.

42. lezzi G, Karjalainen K, Lanzavecchia A: The duration of antigenic stimulation determines the fate of naive and effector T cells. Immunity 1998, 8:89-95

43. Iber D, Maini PK: A mathematical model for germinal centre kinetics and affinity maturation. J Theor Biol 2002, 219:153-175.

44. da Silva Neves MM, González-Garcia MB, Nouws HP, Delerue-Matos C, Santos-Silva A, Costa-García A: Celiac disease diagnosis and gluten-free food analytical control. Anal Bioanal Chem 2010, 397:1743-1753.

45. Aleanzi M, Demonte AM, Esper C, Garcilazo S, Waggener M: Celiac disease: antibody recognition against native and selectively deamidated gliadin peptides. Clin Chem 2001, 47:2023-2028.

46. Gianfrani C, Siciliano RA, Facchiano AM, Camarca A, Mazzeo MF, Costantini S, Salvati VM, Maurano F, Mazzarella G, laquinto G, Bergamo P, Rossi M: Transamidation of wheat flour inhibits the response to gliadin of intestinal T cells in celiac disease. Gastroenterology 2007, 133:780-789.

47. Hook R, Jeeves TA: Direct search solution of numerical and statistical problems. J ACM 1961, 8:212-229.

48. Gizzatkulov NM, Goryanin II, Metelkin EA, Mogilevskaya EA, Peskov KV, Demin OV: DBSolve Optimum: a software package for kinetic modeling which allows dynamic visualization of simulation results. BMC Syst Biol 2010, 4:109.

49. Motulsky HJ, Christopoulos A: Fitting models to biological data using linear and nonlinear regression. A practical guide to curve fitting. GraphPad Software Inc: San Diego CA; 2003.

50. Agardh D, Lynch K, Brundin C, Ivarsson SA, Lernmark A, Cilio CM: Reduction of tissue transglutaminase autoantibody levels by gluten-free diet is associated with changes in subsets of peripheral blood lymphocytes in children with newly diagnosed coeliac disease. Clin Exp Immunol 2006, 144:67-75.

51. Information resource about Celiac Disease. [http://www.celiac.com]

52. Xia J, Siegel M, Bergseng E, Sollid LM, Khosla C: Inhibition of HLA-DQ2mediated antigen presentation by analogues of a high affinity 33residue peptide from alpha2-gliadin. J Am Chem Soc 2006, 128:1859-1867.

53. Kapoerchan W, Wiesner M, Overhand M, van der Marel GA, Koning F, Overkleeft HS: Design of azidoproline containing gluten peptides to suppress CD4+ T-cell responses associated with celiac disease. Bioorg Med Chem 2008, 16:2053-2062. 
54. Siegel M, Xia J, Khosla C: Structure-based design of alpha-amido aldehyde containing gluten peptide analogues as modulators of HLA-DQ2 and transglutaminase 2. Bioorg Med Chem 2007, 15:6253-6261.

55. Xia J, Bergseng E, Fleckenstein B, Siegel M, Kim CY, Khosla C, Sollid LM Cyclic and dimeric gluten peptide analogues inhibiting DQ2-mediated antigen presentation in celiac disease. Bioorg Med Chem 2007, 15:6565-6573.

56. Schuppan D, Junker $Y$, Barisani D: Celiac disease: from pathogenesis to novel therapies. Gastroenterology 2009, 137:1912-1933.

57. Ciccocioppo R, Di Sabatino A, Corazza GR: The immune recognition of gluten in coeliac disease. Clin Exp Immunol 2005, 140:408-416.

58. Benson N, Cucurull-Sanchez L, Demin O, Smirnov S, van der Graaf P: Reducing systems biology to practice in pharmaceutical company research; selected case studies. Adv Exp Med Biol 2012, 736:607-615.

59. Agoram BM, Demin O: Integration not isolation: arguing the case for quantitative and systems pharmacology in drug discovery and development. Drug Discov Today 2011, 16:1031-1036.

doi:10.1186/1752-0509-7-56

Cite this article as: Demin et al:: Modeling of celiac disease immune response and the therapeutic effect of potential drugs. BMC Systems Biology 2013 7:56.

\section{Submit your next manuscript to BioMed Central and take full advantage of:}

- Convenient online submission

- Thorough peer review

- No space constraints or color figure charges

- Immediate publication on acceptance

- Inclusion in PubMed, CAS, Scopus and Google Scholar

- Research which is freely available for redistribution 